\title{
Strategies for correcting the workpiece deformation during the manufacturing at the milling process.
}

\author{
Marvin Eggebrecht, M.Sc. ${ }^{1}$, Anthimos Georgiadis, Prof. Dr. ${ }^{1}$, Thomas Wagner ${ }^{1}$ \\ 'Leuphana University of Lueneburg, Institute of Product and Process Innovation (PPI), \\ Volgershall 1, 21339 Lueneburg, Germany, \\ Marvin.Eggebrecht@leuphana.de
}

\begin{abstract}
Clamping forces may influence the machining accuracy of the workpiece. The aim of the work is to develop a clamping system which measures during the process the clamping forces applied on the workpiece. Therefore a special chuck jaw has been developed which measures the strain from the clamping process at each chuck jaw. The chuck jaws were designed for the specific application case with a finite element method. With the information out of the process it is possible to find correlations between workpiece deviations and the clamping force. The project was started to correct errors with the aim of better surface quality and smaller variations in tolerances.
\end{abstract}

Key words: Clamping system, chuck jaw, milling process, workpiece monitoring, workpiece deformations

\section{Introduction}

A progressive development in the field of metal cutting machine tools, and constantly increasing demands on new processing technologies require increasingly smaller tolerances in manufacturing. The processing results of a workpiece depend crucially of the machining center and the used clamping system [1].

There are various methods to clamp in a workpiece. On the market are hydraulic, pneumatic, and mechanical chucks available which are not smart. These chucks clamp the workpiece with a specific chuck jaw that consist normally of a basic and a top jaw. This article regards a mechanical four chuck jaw which is used in a milling process. Each top jaw of this clamping system is specialized with a strain gauge sensor. With the information from the sensors it is possible to detect influences of the clamping forces into the quality of a milling process due to the possible deformation of the workpiece.

Cause of cost - effective workpiece producing and increasingly machine parameters such as the feed rate or the depth of cut extreme vibrations are possible. These vibrations could create chatter marks at the final workpiece. Other researchers are working in this area to solve the problem with the help of an active tool holding device. In time of high complex milling machines the requirements of the tools, the tool clamping and the workpiece clamping system are crucial [2].

The next picture shows the development of a clamping system with strain gauge sensors.

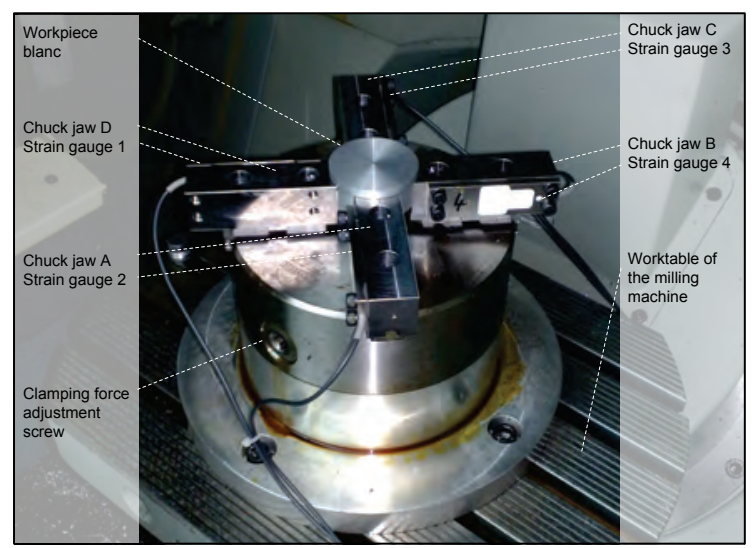

Fig. 1. Test setup for the intelligent clamping system

With this system it is possible to increase the workpiece quality and find out the correlations of the clamping force and the deviations of the produced workpiece.

\section{The concept and implementation}

To achieve a high quality manufacturing the process must be analyzed. There are several steps which have a decisive influence on the outcome. The first step starts with a CAD / CAM simulation of the final workpiece in order to achieve the expected deformation. In the second step a strategy must be found to 
minimize the deformation. This is achieved with corresponding NC code improvements. In the third step the milling process is running. During this process the forces at each chuck jaw is measured to obtain conclusions about the deformation. Is the actual running process all right then there is no correction needed. If directly on the workpiece strong deviations are measured the milling process needs a correction.

To measure these deviations a special chuck jaw with a strain gauge is developed. The following picture shows the chuck jaw in detail.

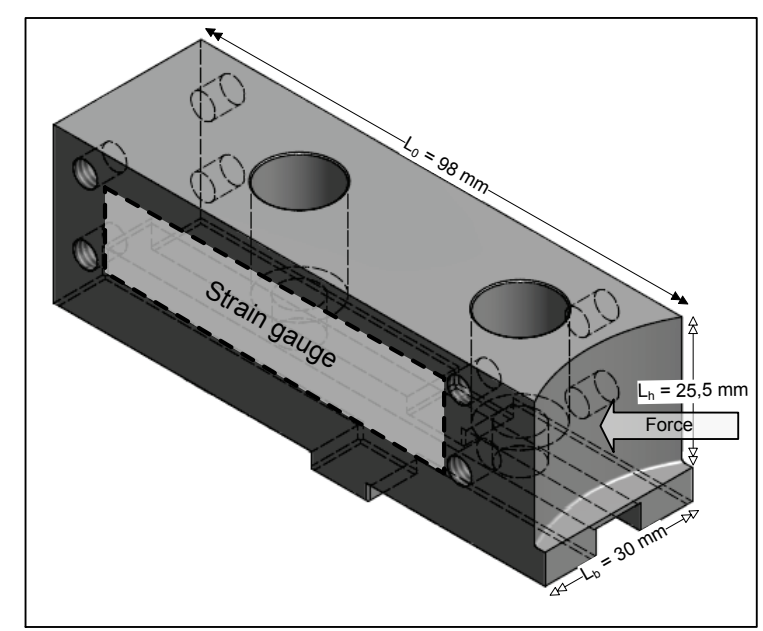

Fig. 2. Chuck jaw with strain gauge

The used material for the chuck jaw is tool steel with the material number 1.0037. The steel parameters are shown in the following table.

Tab. 1: Chuck jaw parameters

\begin{tabular}{|c|r|}
\hline Tensile strength $\mathbf{R}_{\mathbf{m}}$ & $360 \mathrm{~N} / \mathrm{mm}^{2}$ \\
\hline Elastic limit $\boldsymbol{R}_{\mathbf{p}, 0,2}$ & $235 \mathrm{~N} / \mathrm{mm}^{2}$ \\
\hline Modulus of elasticity $\mathbf{E}$ & $210000 \mathrm{~N} / \mathrm{mm}^{2}$ \\
\hline Shear modulus $\mathbf{G}$ & $81000 \mathrm{~N} / \mathrm{mm}^{2}$ \\
\hline
\end{tabular}

These parameters are necessary to calculate the maximum forces which the chuck jaw can absorb without being destroyed. It is important to know the maximum change in length by the maximum force at the chuck jaw to choose the right strain gauge. This strain gauge must work with a high sensitivity. To calculate the maximum change in length $\Delta \mathrm{L}$ of the strain gauge the following formula is used.

$\varepsilon=\frac{\Delta L}{l_{0}}[3]$

The data for the elongation $\varepsilon$ and $I_{0}$ can be found in the data sheet of the strain gauge. After changing the formula to $\Delta \mathrm{L}$ the change in length can be calculated.

$$
\begin{aligned}
& \Delta L=\varepsilon^{*} l_{0} \\
& l_{0}=0,0762 m ; \quad \varepsilon_{\max }=500 \frac{\mu m}{m} ; \\
& \Delta L_{\max }=500 \frac{\mu m}{m} * 0,0762 m=38,1 \mu m
\end{aligned}
$$

The result shows that the strain gauge can work in a field in theory between $0 \mu \mathrm{m}$ and $38,1 \mu \mathrm{m}$. After some stress tests with the strain gauge it is possible to measure with high accuracy the change in length of the chuck jaw.

In the next step it is important to know which force is needed at one chuck jaw to reach the maximum change in length of the strain gauge. If this is known it is significant that the chuck jaw and the complete clamping system is working in this area and is not destroyed. In the table 2 it is depicted the maximum load data of the clamping system.

Tab. 2: Parameters of the clamping system

\begin{tabular}{|c|c|}
\hline Max. tension & $55000 \mathrm{~N}$ \\
\hline $\begin{array}{c}\text { Max. tension at each } \\
\text { chuck jaw }\end{array}$ & $13750 \mathrm{~N}$ \\
\hline $\begin{array}{c}\text { Max. clamping force } \\
\text { on clamping screw }\end{array}$ & $140 \mathrm{Nm}$ \\
\hline
\end{tabular}

The needed force to achieve a change in length of $38,1 \mu \mathrm{m}$ at the chuck jaw by using the described material is in the following calculated.

$$
\begin{aligned}
& F_{x \max }=\frac{A^{*} E^{*} \Delta L_{\text {max }}}{l_{0}}[4] \\
& F_{x \max }=\frac{30 m^{*} 25,5 m m^{*} 210 \frac{\mathrm{KN}}{\mathrm{mm}^{2}} * 38,1 \mu m}{98 m m} \\
& F_{x \max } \approx 64000 \mathrm{~N}
\end{aligned}
$$

The calculated result characterize that the strain gauge is well chosen for this task with a coefficient of safety round about four. The reason for this is the technical maximum load of one chuck jaw $(13750 \mathrm{~N})$. From this calculations the function $y=1691,1^{*} x-1^{*} 10^{-11}$ is derived. The next graph represents the content between the force at the chuck jaw and the change in length which has linearity in the Hooke's range [5]. This linearity is the reason for using strain gauges to measure indirectly the force of the clamping system at the workpiece. 


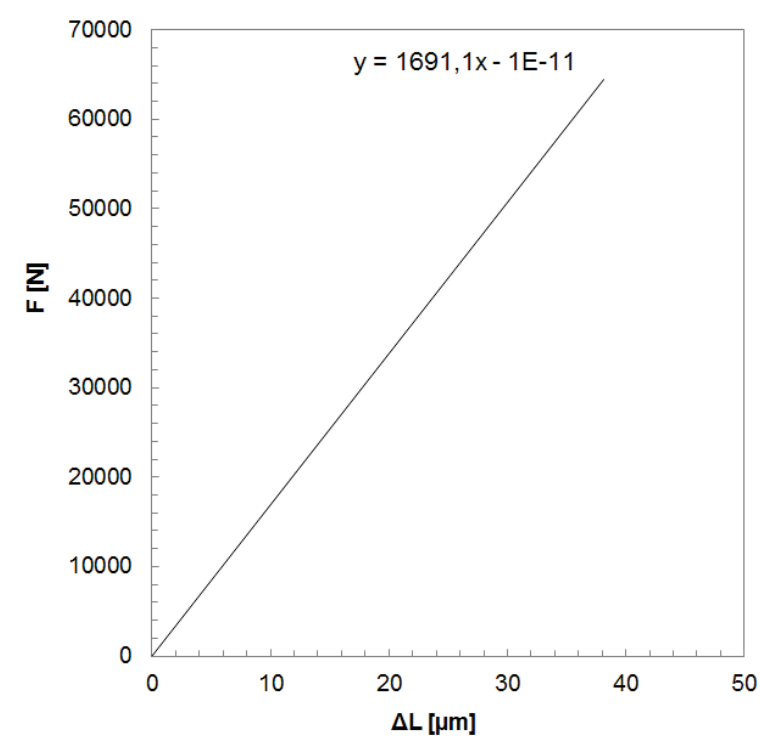

Fig. 3. Stress - strain - diagram (Hooke's range)

With the finite element method (FEM) the chuck jaw is simulated to check the maximum load. With software using FEM and the assumed maximum load of $13750 \mathrm{~N}$ the chuck jaw is analyzed.

The outcome of this FEM analysis shows that the chuck jaw is sufficiently dimensioned. Only at a force bigger than $15000 \mathrm{~N}$ the chuck jaw has a too great von Mises tension and the elastic limit of $235 \mathrm{~N} / \mathrm{mm}^{2}$ is reached. When the elastic limit is exceeded the chuck jaw receives an irreversible plastic deformation. The next figure shows the results of the FEM analysis in false color representation.

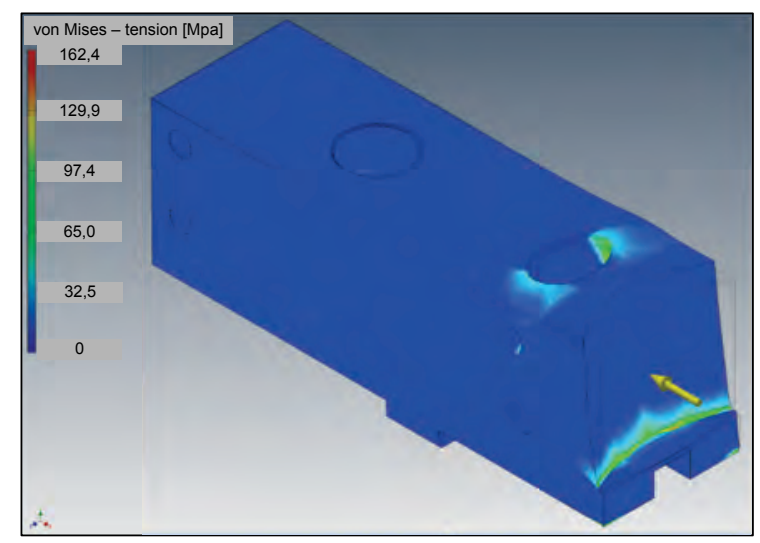

Fig. 4. FEM analysis with a load of $13750 \mathrm{~N}$

All these calculations are important to dimension the clamping system properly.

\section{Performed tests with the sensor system}

The four-jaw chuck which is illustrated in figure 1 is a standard clamping system for the milling process. The base jaws are standard and the developed top jaws can simply be screwed onto the base jaws. The workpiece is a cylinder made of aluminum with the material name
AIMgSi1. In the following table the material properties are listed.

Tab. 3: Workpiece parameters

\begin{tabular}{|c|r|}
\hline Tensile strength $\mathbf{R}_{\mathrm{m}}$ & $310 \mathrm{~N} / \mathrm{mm}^{2}$ \\
\hline Elastic limit $\mathbf{R}_{\mathrm{p}, 0,2}$ & $255 \mathrm{~N} / \mathrm{mm}^{2}$ \\
\hline Modulus of elasticity $\mathbf{E}$ & $70000 \mathrm{~N} / \mathrm{mm}^{2}$ \\
\hline Shear modulus $\mathbf{G}$ & $27000 \mathrm{~N} / \mathrm{mm}^{2}$ \\
\hline
\end{tabular}

For the test environment the workpiece is tightened to $30 \mathrm{Nm}$ by using a torque wrench. This torque produces a total force of $\approx 2800 \mathrm{~N}$ at the clamping system. This is measured with the help of the developed intelligent chuck jaw.

After the milling process the cylindrical workpiece has a wall thickness of $5 \mathrm{~mm}$. If then the workpiece is clamped with a too great force it can break in during the milling process. As a result of this the final workpiece could have to large deviations. For testing these relationships there are some experiments to examine the uniformity of the clamping force. Several times the workpiece was clamped and declamped. The raw data is shown the next graph.

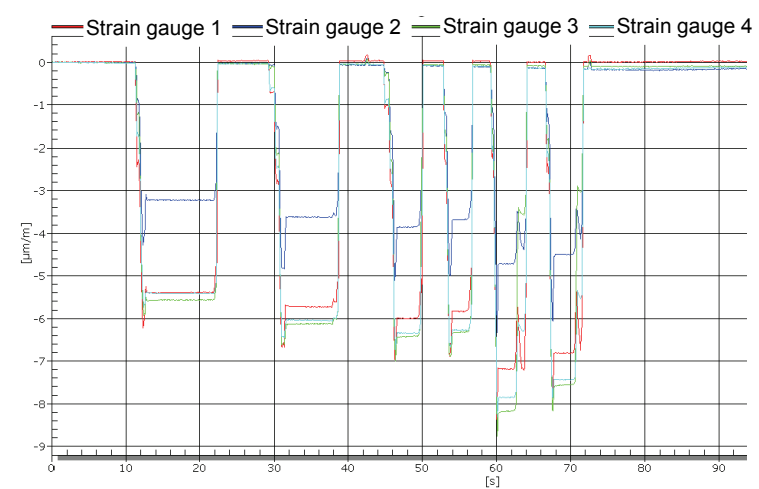

Fig. 5. Raw data of the strain gauges during some clamping processes of $30 \mathrm{Nm}$

By viewing the figure 5 there are deviations at each strain gauge. The largest deviation has the strain gauge 2 with the half of the elongation. These deviations are due to an inaccurate chuck quality. Further tests with other clamping forces confirm these deviations.

\section{Results of the tests}

After the milling process of the workpiece the correlations of the different clamping generate chatter marks and tolerances at the workpiece in the area of the chuck jaw $A$ with the strain gauge 2 (see fig. 1.).

The workpiece deviations are checked with the help of a roundness measurement from a coordinate measuring machine. Indeed there a deviations bigger than $10 \mu \mathrm{m}$ cause of inaccurate clamping conditions. The measured 
and calculated clamping forces are shown in the coming table.

Tab. 4: Force measurement results by a clamping force of $30 \mathrm{Nm}$

\begin{tabular}{|c|c|c|}
\hline & $\begin{array}{c}\text { Change of } \\
\text { the chuck } \\
\text { jaw in } \\
\text { length } \Delta \mathrm{L}\end{array}$ & $\begin{array}{c}\text { Clamping } \\
\text { force } \mathbf{F}\end{array}$ \\
\hline Chuck jaw A & $-0,276 \mu \mathrm{m}$ & $\approx-467 \mathrm{~N}$ \\
\hline Chuck jaw B & $-0,461 \mu \mathrm{m}$ & $\approx-780 \mathrm{~N}$ \\
\hline Chuck jaw C & $-0,467 \mu \mathrm{m}$ & $\approx-790 \mathrm{~N}$ \\
\hline Chuck jaw D & $-0,436 \mu \mathrm{m}$ & $\approx-737 \mathrm{~N}$ \\
\hline Sum & $-1,640 \mu \mathrm{m}$ & $\approx-2774 \mathrm{~N}$ \\
\hline
\end{tabular}

Normally at each chuck jaw should be a clamping force of round about $700 \mathrm{~N}$ to the workpiece. The deviation of the clamping force at chuck jaw $A$ is the reason for the imprecise manufacturing. The final workpiece is presented at the next picture.

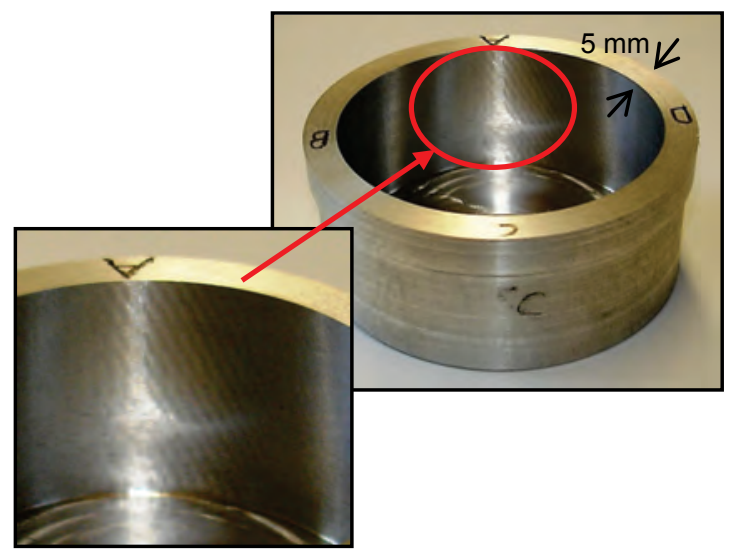

Fig. 6. The final workpiece

Due to the lower tension at the chuck jaw $A$ $(\approx 467 \mathrm{~N})$ vibrations are occurred in the red area. As a result of this chatter marks are visible of the test workpiece.

\section{Summary and Conclusions}

When clamping a workpiece the clamping system has a crucial role for the final manufacturing result. This is demonstrated by the performed experiments. The developing of the chuck jaw which can measure forces was the key step to find out correlations between clamping forces and manufacturing variances. This developed system is a different approach to improve the production quality in a machine guided process.

In a further step it must decide how to deal with the new data. For this purpose various approaches are considered. Some possibilities are being reviewed now. The first is to implement the data of the clamping system in the software of the machine control to correct the error during the manufacturing process. Before the implementation the data must be evaluated with a statistical or a predictive model. The second is a standalone solution with an automatically clamping system. This system should regulate in real time the ideal clamping force for a high accuracy manufacturing process. Another conceivable approach is the combination of the two explained possibilities.

\section{References}

[1] B. Perovic, Handbuch Werkzeugmaschinen: Berechnung, Auslegung und Konstruktion, p. 293-295 (2006);

[2] A. Boldering, A. Raatz, An active tool holding device, German Academic Society for Production Engineering (WGP), p. 1-3 (2012); doi: 10.1007/s11740-012-0402-x;

[3] E. Hering, Sensoren in Wissenschaft und Technik. Funktionsweise und Einsatzgebiete., $p$. 323 (2012);

[4] M. Eggebrecht, Strategien zur Korrektur der Werkstückdeformation während der Bearbeitung beim Fräsprozess, p. 50 (2012);

[5] S. Hesse, G. Schnell, Sensoren für die Prozessund Fabrikautomation. Funktion - Ausführung Anwendung, p. 155 (2012); 